\title{
MICROSTRUCTURAL CHARACTERIZATION AND MECHANICAL PERFORMANCE ALONG THE THICKNESS OF ELECTRON BEAM WELDED STABILIZED AISI 321 STAINLESS STEEL
}

\author{
Ajay Sharma ${ }^{1, *}$, Vineet Prabhakar ${ }^{2}$, Sandeep Singh Sandhu ${ }^{3}$ \\ ${ }^{1}$ Punjab Technical University, Kaputhala (Punjab), India \\ ${ }^{2}$ Department of Mechanical Engineering, Chandigarh University, Garuan, Mohali \\ (Punjab), India \\ ${ }^{3}$ Department of Mechanical Engineering, Quest Infosys Foundation Group of \\ Institutions, Jhanjheri, Mohali-140307 (Punjab), India
}

Received 01.12.2020

Accepted 22.02.2021

\begin{abstract}
The Electron Beam welding (EBW) process was employed to fabricate $18 \mathrm{~mm}$ thick fully penetrated butt welds of AISI 321 stainless steel. Nail-shaped weld wide at the top and narrow at the bottom was obtained. Characterization of the weld joint was carried out using optical microscopy, scan electron microscopy, X-ray diffraction, microhardness, impact toughness test, and tensile strength test. The microstructure of the weld metal was found to be free from defects like cracks, porosity, etc. The weld metal consisted of the primarily austenitic matrix with skeletal and vermicular morphology of $\delta$-ferrite by the side of the grain boundaries. Carbides of $\mathrm{Cr}$ and $\mathrm{Ti}$ were found in the weld metal after the thermal aging treatment of $750{ }^{\circ} \mathrm{C}$ for 24 hours, as revealed by the XRD analysis. The tensile strength study revealed a maximum strength of $575 \mathrm{MPa}$ at the root of the weld joint in the as-welded state. The maximum impact toughness of $129.3 \mathrm{~J}$ was obtained in the top section of the weld in the as-welded condition. The results in terms of structure-property correlate relationship. This study recommends the effectiveness of EBW for joining $18 \mathrm{~mm}$ thick AISI 321.
\end{abstract}

Keywords: Electron Beam Welding; AISI 321 Stainless steel; Thermal Aging; Metallurgical properties; Tensile strength; Impact toughness; XRD; SEM; Fractography

${ }^{*}$ Corresponding author: Ajay Sharma,er.dishu@gmail.com 


\section{Introduction}

Weldings of thick sections of structures made using stainless steel alloys are commonly employed in nuclear, oil, and chemical industries. The industries use conventional welding processes like GTAW and GMAW to weld thick sections due to cost constraints. These conventional welding processes are time-consuming, use multipass and multilayer to complete the weld, and due to this large amount of heat is infused into the weld, which leads to distortion, and hence they are less productive [1]. On the other hand, high-density techniques viz. laser and electron beam comparatively have high welding speed, deep weld penetration, and less distortion. Therefore, these high-end processes are used to join the thicker sections, which have a larger depth to width ratio [2, 3]. High-end techniques used for welding either use laser beam or electron beam to weld materials used in high-temperature applications. Wherein laser beam welding can be performed in any atmosphere. However, for thicker sections, powerful lasers are required. On the other hand, vacuum is required for electron beam welding, but due to the large energy density of electron beams, a less powerful electron beam can weld thicker sections in a single pass. Thus, electron beams are preferred over laser beams to weld the thick sections. However, the variations at the microscopic levels and mechanical performance along with the thickness after being welded by electron beam welding for thicker sections is the considerable knowledge gap that must be exploited to achieve maximum potential.

Austenitic stainless steels (ASS) find application in nuclear power stations, boilers, superheaters, chemical plants, etc. They possess desirable mechanical properties and have high resistance to oxidation at elevated temperatures [4-6]. Microstructural changes like the formation of secondary phases ( $\delta$ ferrite, chi, and sigma phases), $\mathrm{Cr}$ and Ti rich metal carbides $\left(\mathrm{M}_{23} \mathrm{C}_{6}, \mathrm{MC}\right)$ are formed in ASS if they are exposed to harsh conditions for long durations of time [7]. However, metals like $\mathrm{Mo}, \mathrm{Ti}, \mathrm{Nb}$, etc. are added to various steels to make them stabilized in harsh conditions [8,9]. In AISI 321 SS Ti is added as a stabilizer that leads to the formation of titanium nitrides and carbides, which restrict the formation of chromium carbides, hence the improvement of the intergranular corrosion resistance properties when AISI 321 SS is exposed to high temperatures for long durations [10]. The intermetallic $\sigma$ phase is also formed when these stabilized steels were exposed to high temperatures. The intermetallic phases' existence deteriorates the mechanical properties and reduces its corrosion resistance also [11-14]. Hajiannia et al. [6] reported that the $\sigma$ phase precipitate in ASS between 600 ${ }^{\circ} \mathrm{C}$ to $1000{ }^{\circ} \mathrm{C}$. Guan et al. [4] stated that carbides got precipitated in AISI 321 due to heating and cooling cycles of the welding process, which further transformed to $\sigma$ phase after aging at a high temperature of $700^{\circ} \mathrm{C}$. Austenitic steels are welded using various conventional welding processes like gas tungsten arc welding (GTAW), plasma arc welding (PAW) [15-17]. These processes have high heat input and, as a consequence, a slow cooling rate which leads to coarse grain structure, having vermicular dendritic morphology $[18,19]$. However, High-end welding techniques like laser beam welding (LBW), electron beam welding (EBW) use low heat input to weld thick sections, and as a result, the weld beads cool rapidly. Therefore fine grain structure is obtained by giving improved mechanical performance and corrosion resistance compared to conventional welding processes [20]. S.C. T.jong et al. [21] concluded that due to fast cooling of electron beam and laser welded AISI 316L altered the solidification mode and hence deteriorates the mechanical properties of the weld. 
Yailbas et al. [22]concluded that microhardness got decreased along the weld axis due to the depletion of Ti in the melt-solid boundary of EBW welded 321 plates. At the fusion zone, the columnar dendritic structure was observed and transverse microcracks appeared along the weld center line in Ti depleted zone. Akbari et al. [23] found a very fine martensitic structure in the weld zone because of higher cooling rates of laser beam welding. Green et al. [5] showed that the aging of substrate and weld zone of AISI $321 \mathrm{SS}$ tubes is complicated because of the formation of the ferrite phase during the aging process. Precipitation of MC types carbides at grain boundaries due to aging treatment have been reported by many authors [4, 5, 11, 24-26]. Guan et al. [27] concluded that needle type $\sigma$-phase in weld metal acted as a stress concentration factor and therefore resulted in crack formation at the interphase.

In the present research work, the variations at the microstructure level and mechanical performance along the thickness of $18 \mathrm{~mm}$ thick plates of AISI 321 welded using electron beam are investigated in as-weld state and after imparting aging treatment. This experimental work was done with the primary goal of investigating the microstructure and its variations due to aging treatment at the top, middle, and bottom sections of the weld. Moreover, this will define its advantages and boundaries.

\section{Material and methods}

The base material used in the present research work was AISI $321 \mathrm{SS}$ in the form of $18 \mathrm{~mm}$ thick hot rolled plates of size $200 \mathrm{~mm} \mathrm{X} 75 \mathrm{~mm}$. Its chemical composition as analysed by optical emission spectrometer in weight percentage was $19 \% \mathrm{Cr}, 12 \% \mathrm{Ni}$, $0.08 \% \mathrm{C}, 2 \% \mathrm{Mn}, 0.75 \% \mathrm{Si}, 0.045 \% \mathrm{P}, 0.3 \% \mathrm{~S}, 0.5 \% \mathrm{Ti}$ and balance as iron. The plates were subjected to mechanical and chemical cleaning procedures before carrying out the welding to avoid the weld defects that could be due to contaminations like grease, rust, dust, etc., on the surfaces. The plates were machined to make a close square butt joint. The backing plate, as shown in Fig. 1 of AISI 321 SS was used to ensure complete penetration of the electron beam so that through thickness welds could be achieved. The backing plate was made an integral part of the joint by welding it with the plates so that the electron beam could impinge inside the backing plate. The backing plates were later removed using the machining process. The Accelerating Voltage (HV), Beam Current (SQ), Focus Coil Current (SL), and welding speed employed were 150 $\mathrm{kV}, 90 \mathrm{~mA}, 2210 \mathrm{~mA}, 600 \mathrm{~mm} / \mathrm{min}$, respectively. The heat input per unit length $(\mathrm{kJ} / \mathrm{mm})$ was calculated using the formula $\mathrm{HI}=[(\mathrm{V} \times \mathrm{I}) \eta \mathrm{X} 60] /[\mathrm{S} X 1000]$ where $\eta=0.95$ (heat source efficiency), $\mathrm{I}=$ beam current $(\mathrm{mA}), \mathrm{V}=$ voltage $(\mathrm{kV}), \mathrm{S}=$ welding speed $(\mathrm{mm} / \mathrm{min})$. The heat input during the welding was calculated to be $1.28 \mathrm{~kJ} / \mathrm{min}$. The welded joint was inspected using the ultrasonic non-destructive technique for the sound quality of the weld. The welded joints were in accordance with a quality level B of the ISO 13919 standard [28]. The specimen for metallurgical, impact and tensile studies were extracted using wire cut EDM from the weldments, and part of these specimens were subjected to aging treatments. Firstly, the isothermal treatments of the specimen extracted from the welds were done by keeping them in a microcontroller-based heating furnace after setting the temperature to $750^{\circ} \mathrm{C}$. After the completion of 24 hours, the specimens were kept in the open air for cooling. This was done to encourage the development of carbides in AISI 321. The duration and the temperature were selected according to the TTT diagram [29]. 


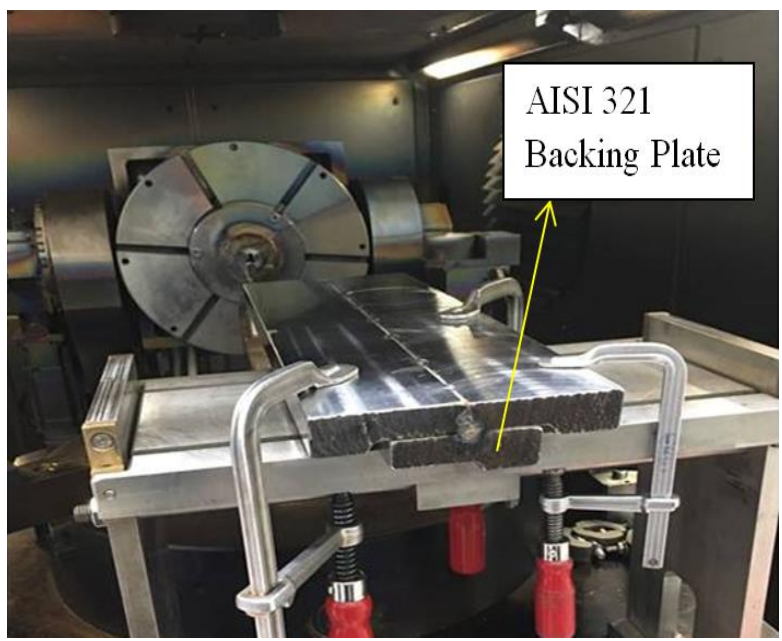

Fig. 1. Photograph showing plate clamped with backing plate.

For the metallurgical characterization of the welds, the specimens were subjected to grinding and polishing treatments using emery paper up to 3000 grit size followed by chemical etching using Marbel's Reagent (consisting of $4 \mathrm{~g}$ of copper sulfate in $20 \mathrm{~mL}$ of hydrochloric acid and $20 \mathrm{~mL}$ of water). After that optical microscopy was used for microstructure evaluation. Scanning electron microscopy (SEM) equipped with elemental composition analysis (EDS) (Zesis EVO MA15) machine was used for carrying out microstructural studies at higher magnification and for EDS. X-ray diffraction analysis (XRD) was done for the identification of phases. The ferrite scope was used to measure the ferrite content at the various points of the weld (BM, WZ, FZ, HAZ) while traversing from top to bottom and across the weld bead at three positions i.e., top middle, and bottom sections. Similarly, Vicker microhardness was carried out using a load of $1 \mathrm{~kg}$ for the dwell time of 20 seconds. Extensive microhardness was performed on two samples, one as welded and the other thermally aged sample according to ASTM: E-384-11e1 standard [30] using a Vickers microhardness testing machine. The toughness of the weld metal was measured using Charpy V notch impact testing at the subzero temperature of $-40{ }^{\circ} \mathrm{C}$ on the specimen of dimension $50 \mathrm{X} 10 \mathrm{X} 10$ mm following ASTM: E23-12cstandard [31]. Transverse tensile test specimens were prepared following ASTM: E8/E8M-13a standard [32] and were subjected to tensile tests on 60-ton universal testing machine for recording the ultimate tensile strength (UTS), yield strength (YS), and percentage elongation. 


\section{Results and Discussion}

Metallographic analysis

Macrostructure

The macrostructure of cross-section across the weld having through thickness penetration, satisfactory fusion boundary and uniform weld zone formation, visibly free from defects is shown in Figure 2Error! Reference source not found.. A typical nailshaped weld, wide at the top and narrow at the bottom region, was observed. In electron beam welding, as the electron beam acts as a heat source and operates in keyhole mode, the weld volume was more at the top than the root region.

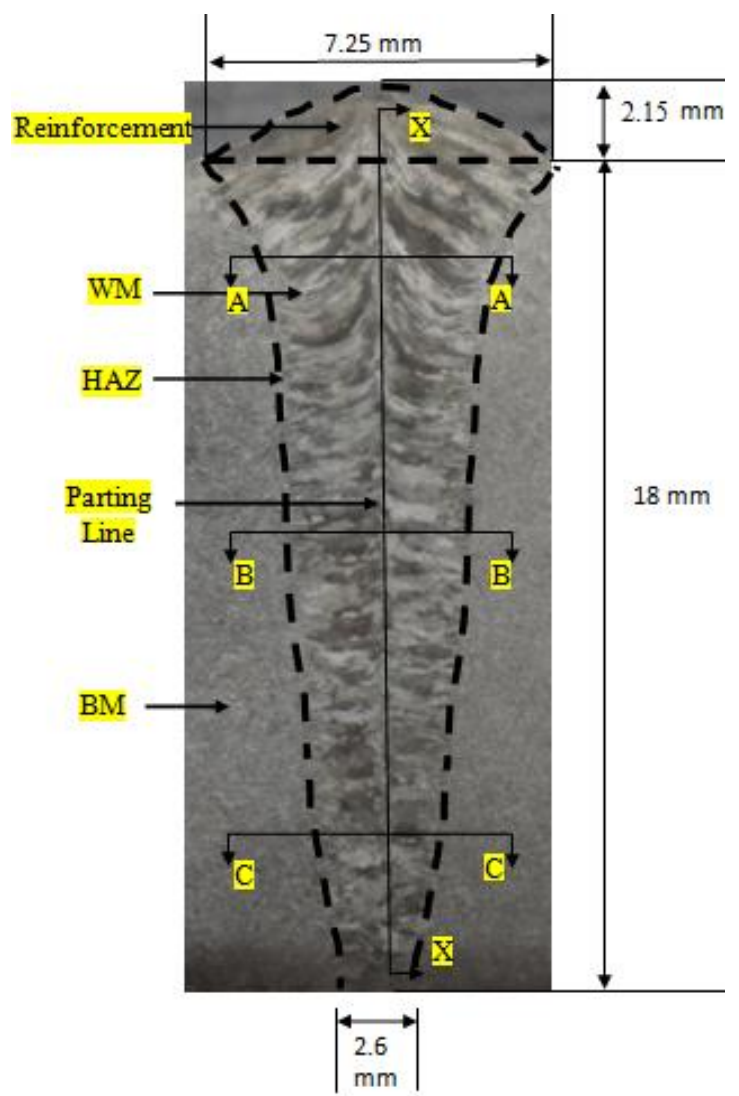

Fig. 2. Macrostructure of EBW welds showing base metal (BM), weld metal (WM) and $A-A, B-B$ and $C-C$ are the axis at top, middle and root region. $X-X$ along the weld center line where microhardness and ferrite content were measured. 


\section{Microstructure}

The optical microstructure and SEM image of the fusion zone are shown in Fig. 3. The base metal shows the ferrite dispersed in the austenite matrix. The grain coarsening can be observed in the fusion zone in the SEM image in Figure 3.
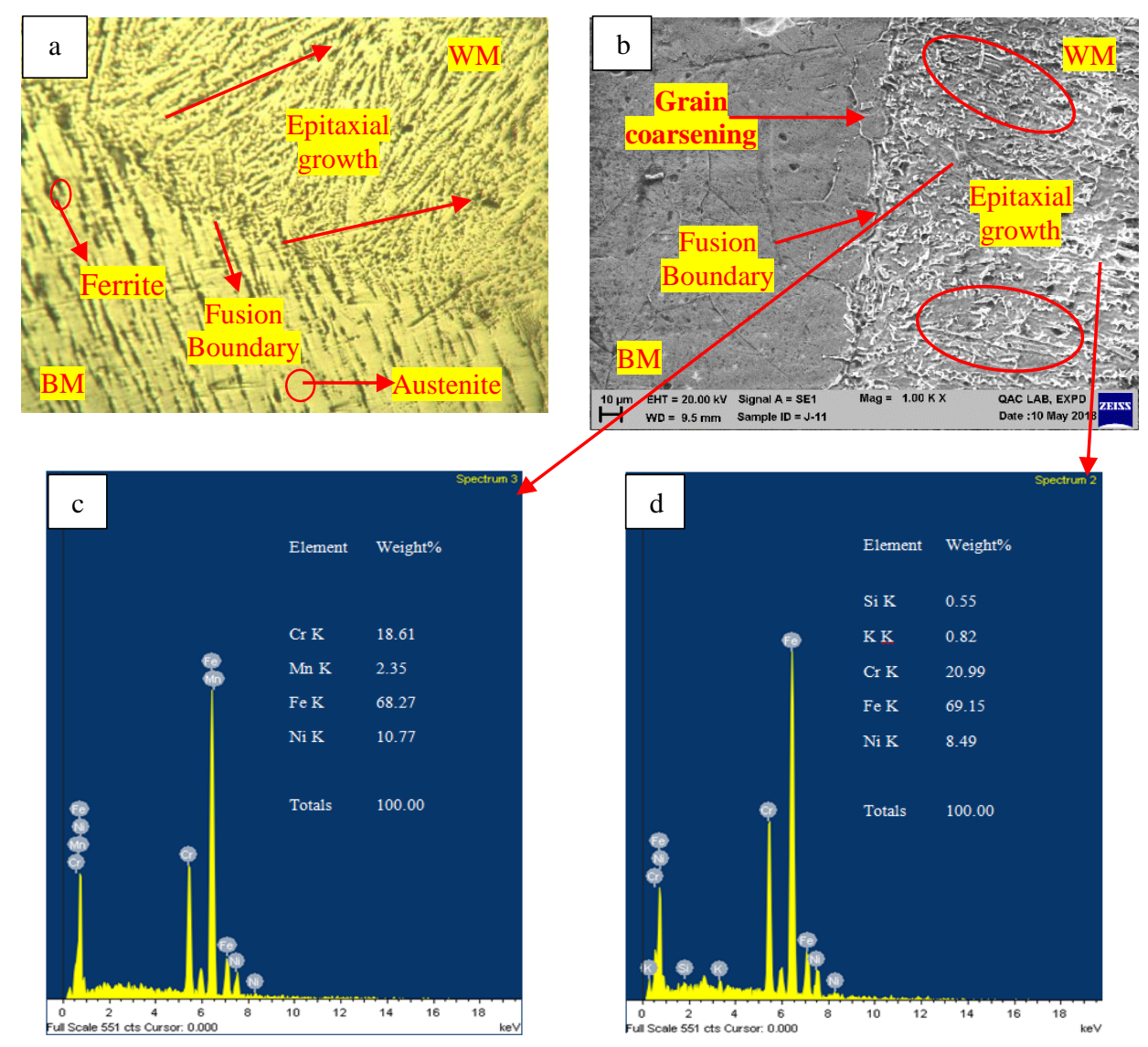

Fig. 3. Microstructure and SEM image of the EBW welds showing base metal (BM), weld metal (WM), and fusion boundary.

This could be attributed to the fact of faster cooling in the fusion boundary. A higher temperature gradient at the fusion boundary was responsible for grain coarsening at the fusion boundary. The epitaxial growth of the austenite was seen near the fusion line. S. Tjong et al. [21] also observed the epitaxial growth in the weld region and attributed it due to a higher solidification rate. The development of the ferrite phase is clearly identified in the SEM image as a white area, and the dark area is the austenite matrix. SEM and EDS were taken on the white area (spectrum 2) and is shown in Figure $3 \mathrm{~d}$, which depicts the increase in the $\mathrm{Cr}$ and $\mathrm{Si}$ content, which are ferrite stabilizing elements. Chih Chun et al. [33] also reported that the Cr and Si content increase plays a vital role in ferrite stabilization. Simultaneously, the EDS at a dark area (spectrum 3) 
shown in Figure $3 \mathrm{c}$ has the higher nickel percentage confirming it as the austenite matrix. Figure 4 and Figure 5 illustrate optical microstructures (at 100X and 200X) of the weld in the as-welded state and after thermal aging treatment of $750^{\circ} \mathrm{C}$ for 24 hours. The weld metal consisted of the primarily austenitic matrix with skeletal and vermicular morphology of $\delta$-ferrite by the side of the grain boundaries. This austenite to ferrite growth may be due to the high cooling rate in the EBW process [34]. The average grain size had decreased from $32.575 \mu \mathrm{m}$ to $21.863 \mu \mathrm{m}$ when we transverse from the top to the bottom of the weld because, at the top, heat dissipation is less than the root region. The volume of the weld pool decreases as we transverse from the top region to the root region of the weld. They are also backing plate at the root region act as the heat sink, which further enhances the heat distribution at the root region. Figure 4(a) shows the microstructure of the top region of the weld, which shows the presence of skeletal structures, and vermicular structures of ferrite dendrites were observed. Figure 4(b) shows a higher magnification of skeletal delta ferrite present in the weld zone. The formation of skeletal, vermicular structure inferred due to the ferrite austenite solidification mode was also reported by R. Kumar et al. [35]. Figure 4(c) shows the microstructure of the middle region of the weldments. The microstructure consists of skeletal delta ferrite stringers along with the lathy ferrites. Figure 4(d) is the magnified view at $200 \mathrm{X}$, shows the development of lathy ferrite in the weld zone. A. Kumar et al. [36] also observed the reduction in the grain size along the weld, and grain spacing was more in the top region and less in the root region.

Figure 4(e) shows the microstructure of the root region of the weld. The microstructure shows the formation of colonies of delta ferrite and cellular austenitic structure; this may be due to ferrite content at the root of the weld. The ferrite analysis was performed using the Fisher ferrite scope and the $\mathrm{X}-\mathrm{X}$ axis, as shown in the macrostructure. The results are shown in Figure 6a designates that the ferrite percentage is higher at the top zone, $7.4 \%$, than the middle zone and root zone, where the values of ferrite content are $6.5 \%$ and $5.1 \%$, respectively. It could be attributed to the superior cooling rate at the root of the weld bead. Figure 5 shows the microstructure of the weld joint after the post-weld thermal aging treatment (PWTA) of $750^{\circ} \mathrm{C}$ for 24 hours.

After aging, the development of carbides in the austenitic matrix can be identified in the microstructure. The formation of $\mathrm{Cr}_{23} \mathrm{C}_{6}$ and $\mathrm{TiC}$ is seen in the XRD analysis of the PWTA weld bead. These carbides might have formed during the solid-state transformation of ferrite to austenite during the PWTA. Fewer ferrites were detected in all regions of the weld metal after aging $24 \mathrm{~h}$ at $750^{\circ} \mathrm{C}$. 


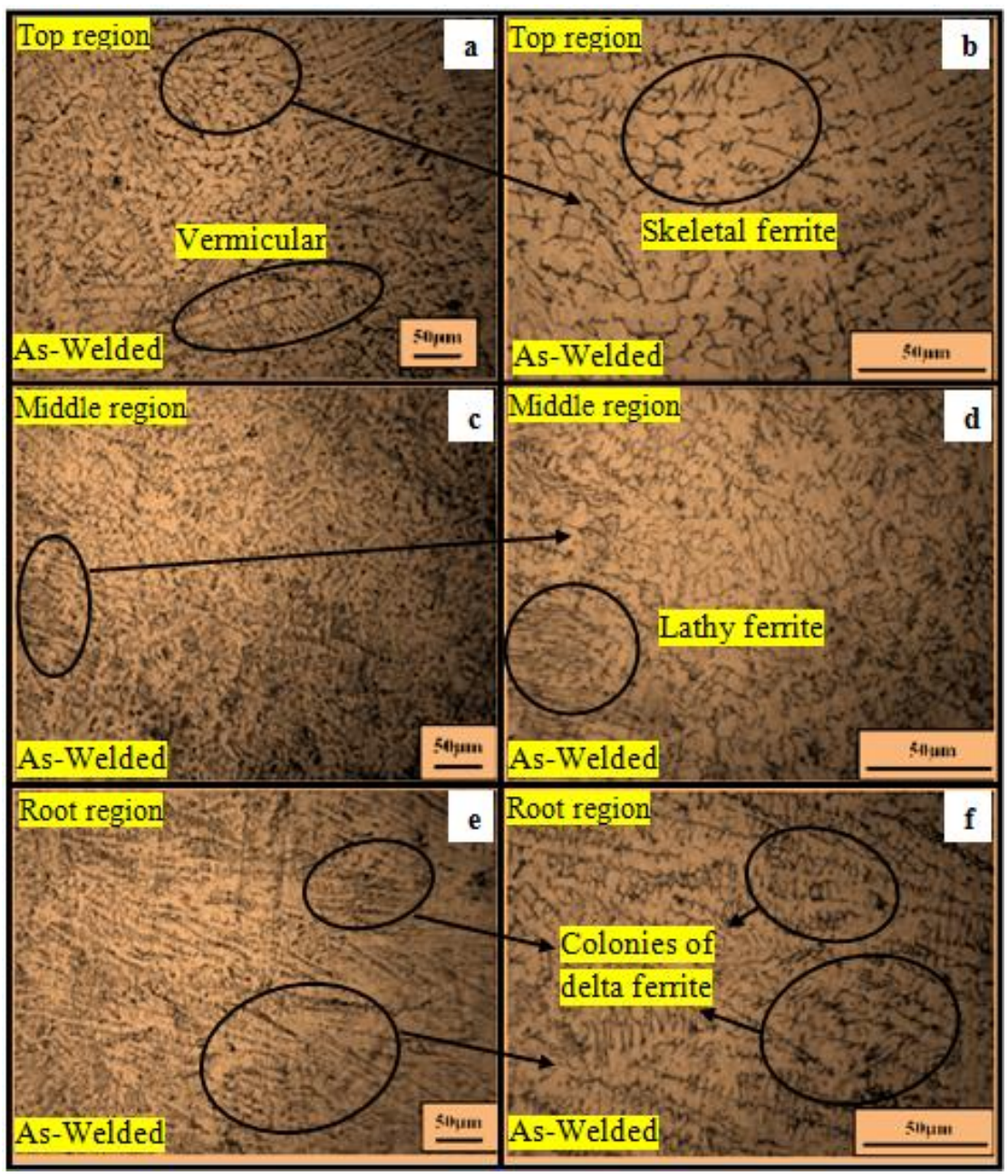

Fig. 4. Microstructure of Electron Beam as-welded joint (a) Top region of weld bead (d) Top region of weld bead at 200X (b) Middle region of weld bead (e) Middle region of weld bead at 200x (c) Root region of the weld zone $(f)$ Root region of the weld zone at $200 x$.

$K$. Guan et al. reported that $\delta$ ferrite, distributing mainly at the grain boundaries, is transformed to $\alpha$-phase during high-temperature aging $[4,37]$. XRD analysis also indicates that the $\delta$ ferrite has decreased after the thermal aging treatment. The result of the XRD analysis is shown in Figure 7 for both as-welded and after PWTA treatment. The peak intensities of (111) $\gamma$ and (200) $\gamma$ austenitic diffraction peaks increase after thermal aging at the expense of $(110) \delta$ and $(200) \delta$ ferrite peaks. This is verified by the Feritscope result in Figure 6b, as a higher volume percent ferrite was recorded in the aswelded specimen than the thermally aged specimen. 


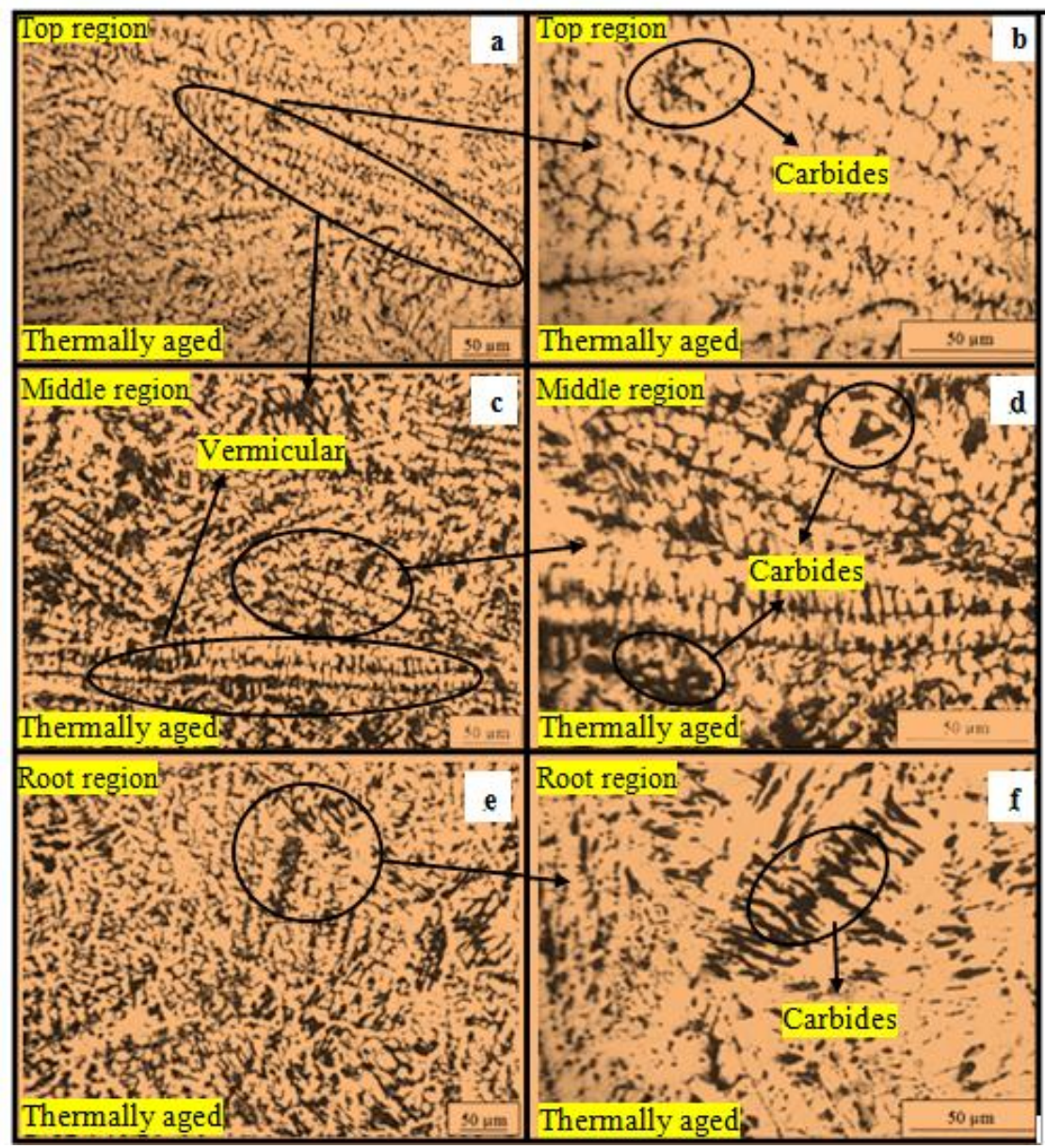

Fig. 5. Microstructure of EBW welded after thermal aging $750{ }^{\circ} \mathrm{C}$ for 24 hours specimen $(a)$ and $(b)$ microstructure at the top region of weld bead $(c)$ and $(d)$ microstructure at the middle region of weld bead $(e)$ and $(f)$ microstructure at root region of the weld bead.

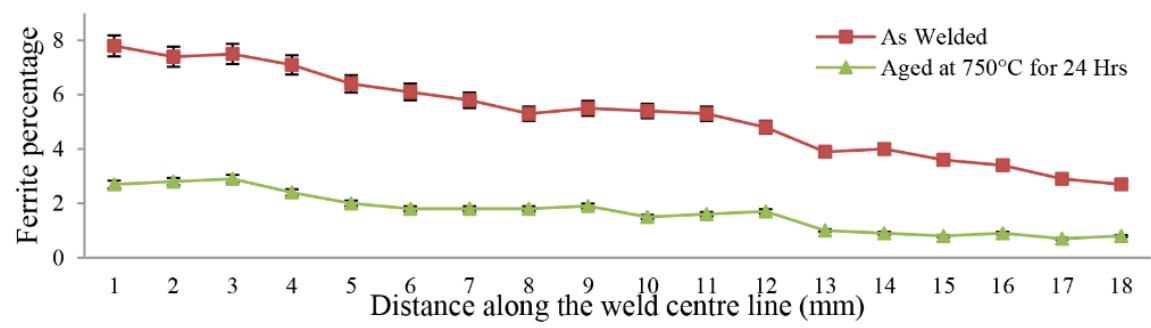

(a) 


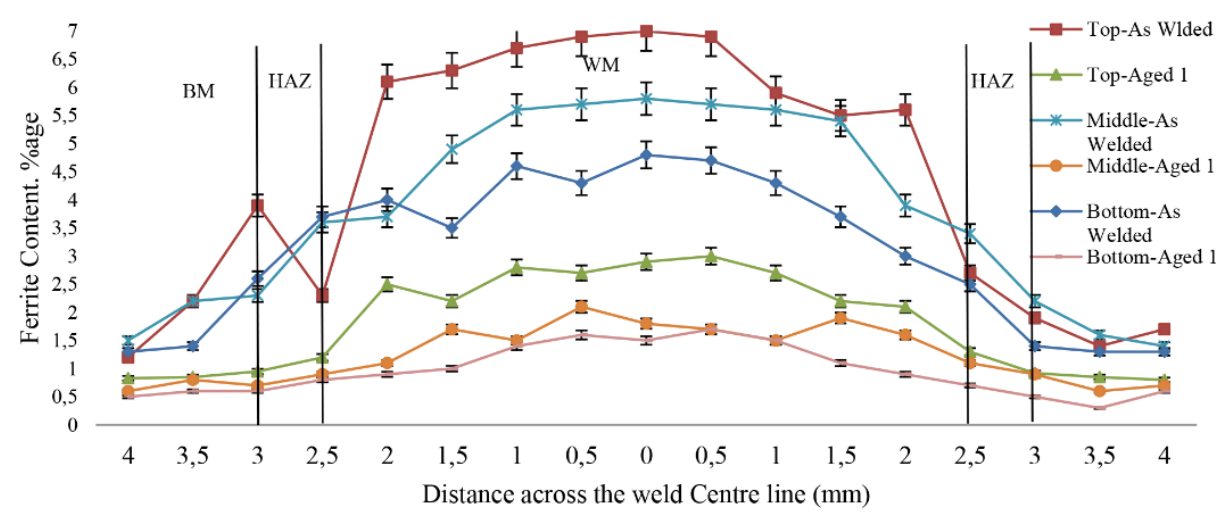

(b)

Fig. 6. The ferrite percentage (a) along with weld bead and (b) across the weld bead in as welded and thermally aged condition.

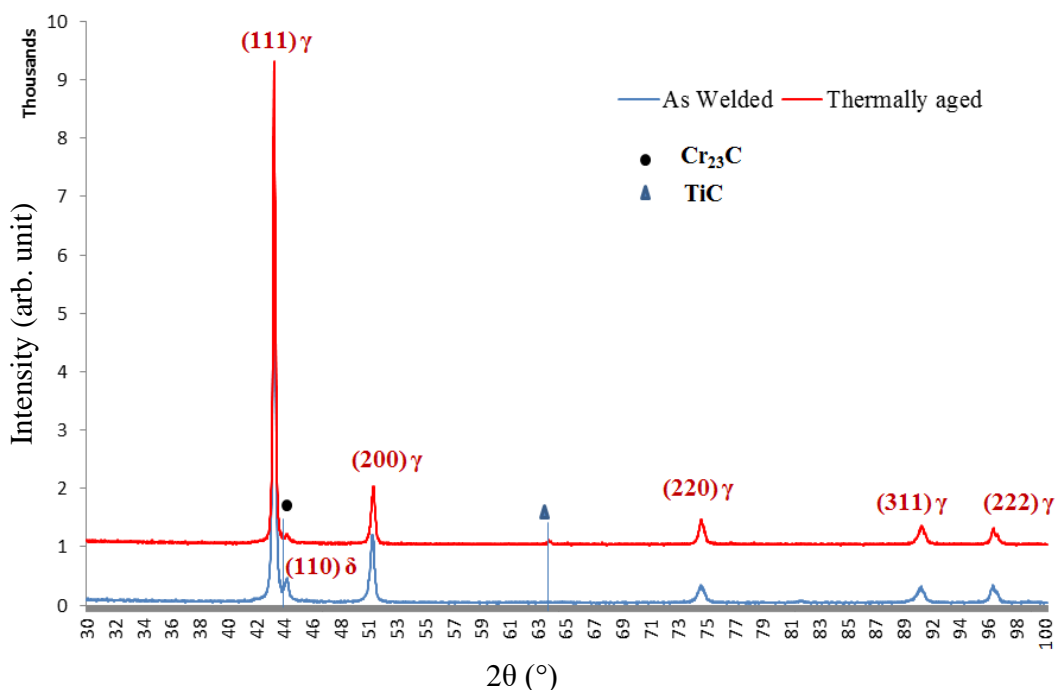

Fig. 7. XRD of as welded and aged samples. (110) $\delta,(211) \delta$ ferrite peaks have reduced in thermally aged samples.

Microhardness analysis

Microhardness across the weld bead in the top, middle, and root regions is shown in Figure 8. The average values of microhardness in the weld zone were measured to be $165.3 \mathrm{HV}, 170.4 \mathrm{HV}$, and $172 \mathrm{HV}$ for top, middle, and root regions of the weld for aswelded samples, respectively. The microhardness values have decreased as we transverse from the top region to the bottom region. This could be attributed to the lesser ferrite content in the middle and root region of the weld. Mithupindi et al. [38] reported that ferrite is softer than austenite. Therefore, the reduction in the ferrite percentage increased the microhardness. Also, the finer grain size in the root and middle 
regions than the top region of the weld is why the increase in hardness. Singh et al. [24] reported that a faster cooling rate in the bottom region due to lesser weld volume had resulted in an increase in microhardness in the bottom region.

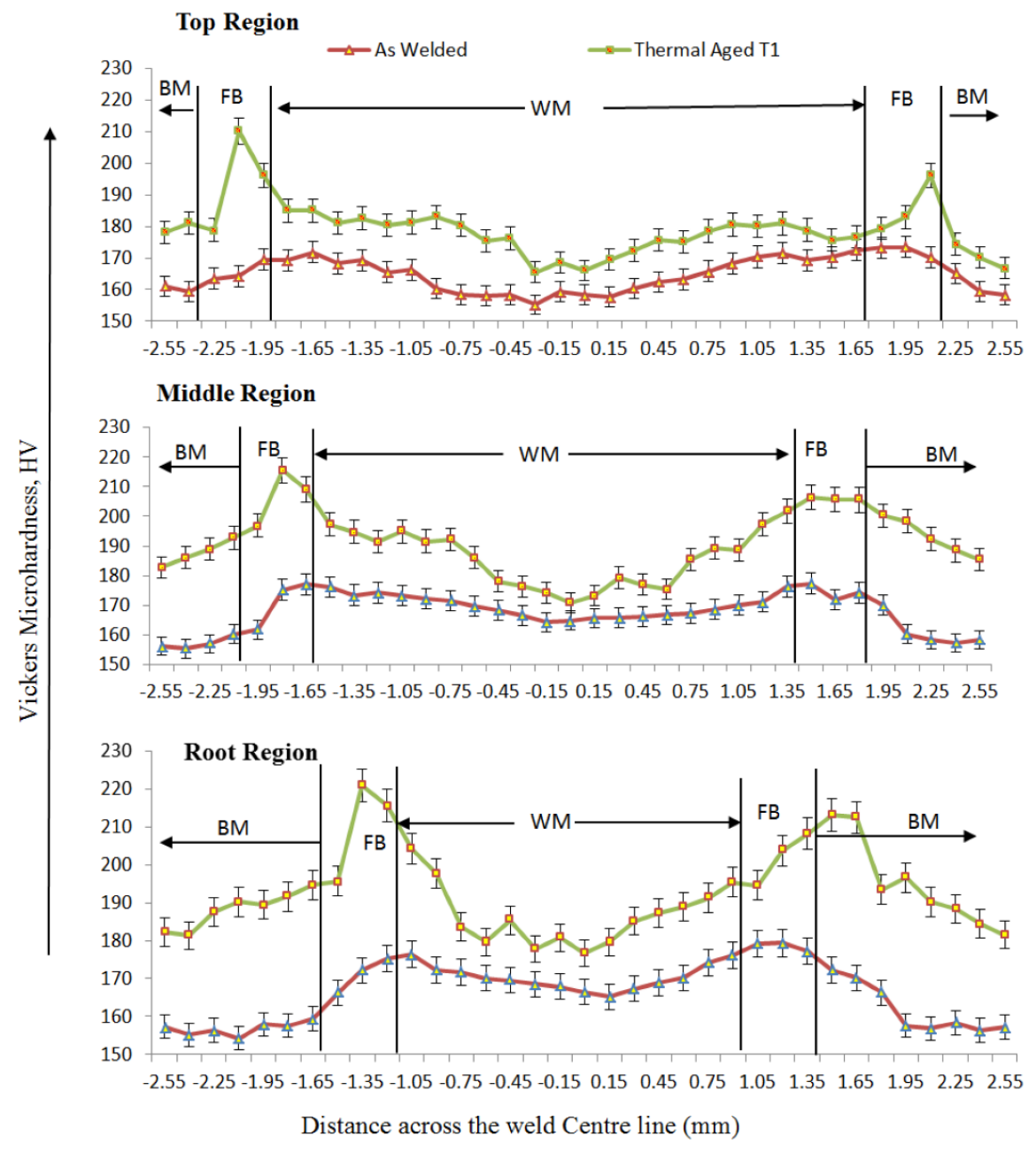

Fig. 8. The Microhardness values across the weld bead in as welded and thermally aged condition.

However, the microhardness values have decreased toward the parting line from the fusion boundary. This could be due to an increase in ferrite content when we transverse toward the parting line (Fig. 6b). The microhardness in the fusion boundary and zone adjutant to the fusion boundary have higher values of microhardnessas compared to the weld zone and base metal. In as welded condition highest microhardnesswas witnessed in the fusion boundary of the middle region. The reason for the increase in the microhardness is due to the fine microstructure formed in the fusion zone. Moreover, 
the residual stress formed during the welding also contributed to this rise in microhardness [34]. The microhardness of the weld zone is higher than the base metal. This could be because of the finer microstructure and precipitation of the secondary phase due to the faster cooling rate in EBW. The aging treatment has increased the microhardness values by approximately $8 \%$ all through the weld bead. The average values were $178.6 \mathrm{HV}, 188.5 \mathrm{HV}$, and $192 \mathrm{HV}$ for top, middle, and root regions of the weld for thermally aged samples, respectively. The increase in the microhardness values of aged samples may be attributed to the decrease in ferrite content owing to the decomposition during the aging process. Mourad et al. [39] have also observed that the ferrite content affects the hardness of the weld metal. They reported that more ferrite would decrease the hardness. The XRD analysis also shows the fall in (110) $\delta$ and (211) $\delta$ ferrite peaks. Also, the formation of $\mathrm{Cr} 23 \mathrm{C} 6$ and $\mathrm{TiC}$ carbides has contributed to the increase in microhardness after the aging treatment.

\section{Mechanical Testing}

Impact Toughness

Charpy V-notch study is significant to apprehend the performance of the welds when they are subjected to sudden load. The impact test results of AISI $321 \mathrm{EBW}$ welds at subzero temperature $\left(-40{ }^{\circ} \mathrm{C}\right)$ are shown in Figure 9. All the specimens have undergone notch deformation. The fractured end clearly suggests that the specimens have absorbed the high energy and behaved in a ductile manner in an as-welded condition. However, the aged samples absorbed less energy before the fracture. This may be due to the formation of $\mathrm{Cr}_{23} \mathrm{C}_{6}$ and $\mathrm{TiC}$ carbides after the post-weld thermal aging. The maximum impact toughness of $129.3 \mathrm{~J}$ was seen in the top region of weld, followed middle region and root region in the as-welded condition.

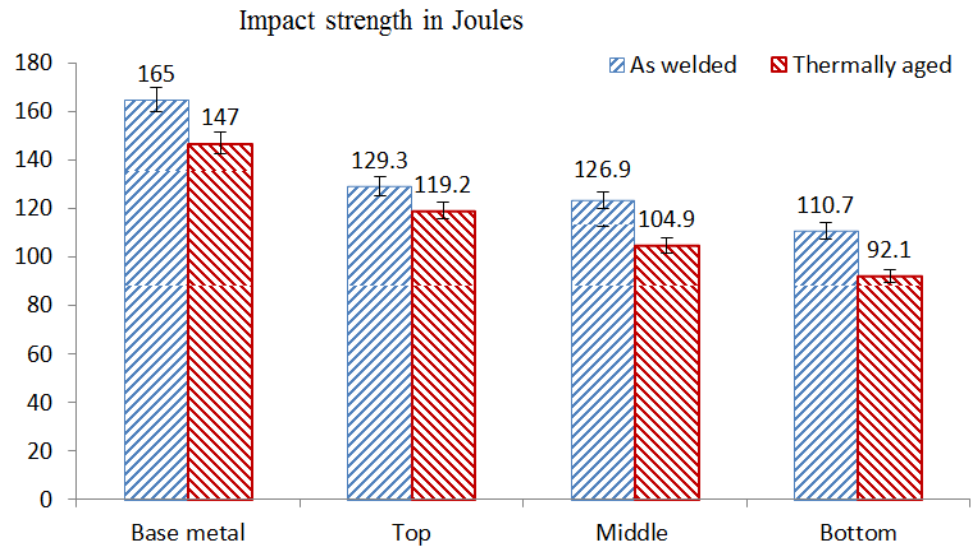

Fig. 9. Impact toughness in as-welded and after PWTA at subzero temperature $\left(-40^{\circ} \mathrm{C}\right)$.

Despite the formation of the ferrite phase and carbides transformation in the welds after the PWTA, the impact strength did not reduce significantly. This may be attributed to the absences of $\sigma$ (sigma), $\psi($ chi) phases. K. R. Kumar et al. [35] reported that undesirable metallurgical phases, like $\sigma, \psi$ formed during the welding process, reduce the impact toughness. The impact energy has reduced along the weld as we 
transverse toward the root of the weld. This may have happened due to the loss in ferrite content (Fig 6a), which further increased the hardness in the root region.

SEM fractography of the as-welded and PWTA specimens were taken from the fractured ends are shown in Fig. . The fractography of the as-welded sample showed ductile dimple morphology, quasi cleavage features, tearing ridges, and voids. The thermally aged sample also showed the same morphology, but flat featureless regions were more dominant than the ductile dimples. $N$. V. Rao et al. [40] have also observed similar trends in the fractographs.

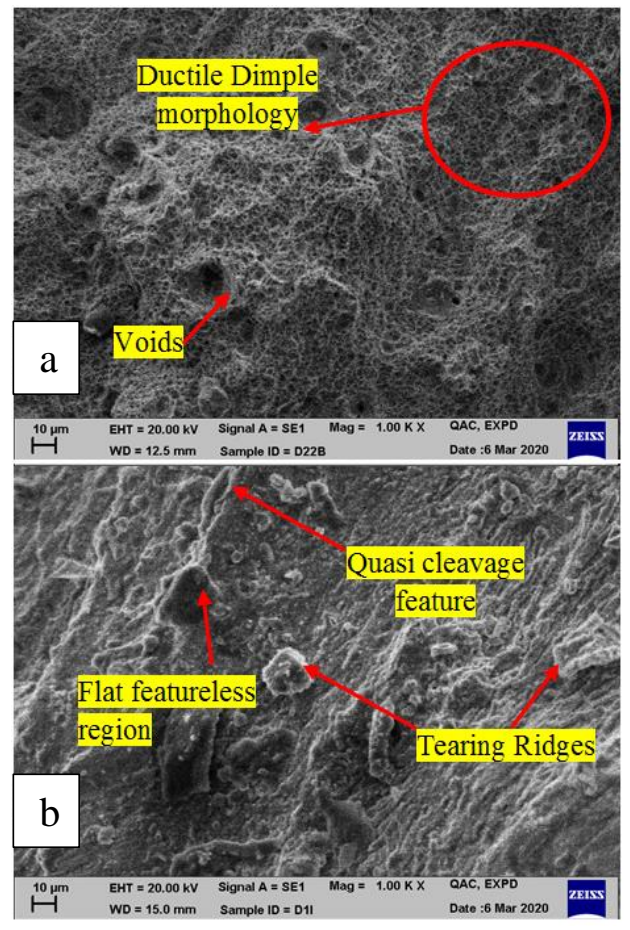

Fig. 10. Fractographs of the impact specimens A (as welded) and $B$ (thermally aged).

\section{$\underline{\text { Tensile Studies }}$}

To evaluate the tensile performance of the welds and to understand whether they can accommodate the industrial requirements, tensile tests were carried out at room temperature. Table 1 shows the tensile test results. All samples failed from the weld metal, which shows that weld metal was weaker than the base metal. This may have accredited because the parting line formed in the EBW is the weakest part of the weld $[34,41]$.

The yield strength of the root region was higher as compared to the middle and the top region. The finer grain structure in the root region may have credited to this increase. The percentage elongation was found to be higher in the root of the weld in both as-welded and thermally aged samples and agreed with the tensile results reported by A.Kumar [41]. This could be because of the finer grain formation due to rapid 
cooling at the root of the weld. Further, the fractured end macrographs of the tensile specimens are shown in Figure 11(c, d).

Table 1. Tensile test results.

\begin{tabular}{llllll}
\hline Specimen & UTS $\left(\mathrm{N} / \mathrm{mm}^{2}\right)$ & $\begin{array}{l}\text { YS } \\
\left(\mathrm{N} / \mathrm{mm}^{2}\right)\end{array}$ & $\begin{array}{l}\text { Elongation } \\
(\mathrm{mm})\end{array}$ & $\begin{array}{l}\text { \%age } \\
\text { elongation }\end{array}$ & $\begin{array}{l}\text { Location of } \\
\text { fracture }\end{array}$ \\
\hline AISI 321 & 585 & 240 & 13.8 & 55 & - \\
AW Top & 548 & 240 & 11.31 & 45.24 & Weld \\
AW Middle & 582 & 263 & 13.7 & 52.8 & Weld \\
AW Root & 551 & 265 & 19.5 & 61.44 & Weld \\
TA Top & 511 & 246 & 16.48 & 65.92 & Weld \\
TA Middle & 557 & 268 & 17.33 & 69.32 & Weld \\
TA Root & 558 & 272 & 18.33 & 73.32 & Weld \\
\hline
\end{tabular}
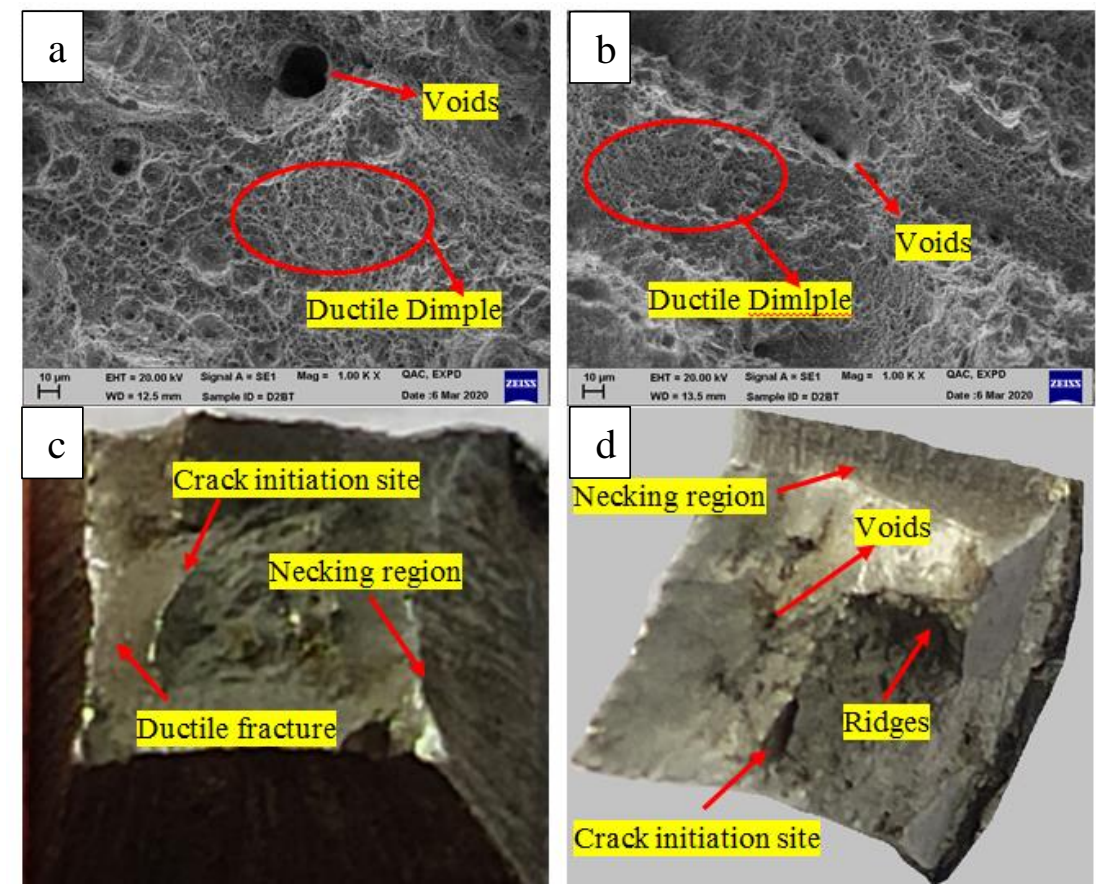

Fig. 11. Fractographs of the Tensile specimens (a) as welded, (b) thermally aged and fracture ends of (c) as welded, (d) thermally aged.

The light gray region in Figure 11(c, d) depicts the ductile behavior of the material. Crack initiation sites and the necking regions are clearly observed in the macrographs. Arrows show void formation and ridges in Figure 11d of the aged specimens. This is due to the pull force applied in the tensile test. Fractured ends of the tensile samples were examined using SEM. Images were obtained for both as-welded and PWTA samples and shown in Fig. 1(a,b). It was observed that the fracture was completely ductile in nature as dimple morphology is seen in both as-welded and 
thermally aged samples. Voids are also seen on the fracture surface of both samples. A large hole has been possibly nucleated from the region where carbide precipitation had occurred [42].

\section{Conclusions}

The following conclusion can be incurred from metallurgical, microhardness, impact toughness, and tensile strength studies of EB welded joints of $18 \mathrm{~mm}$ thick AISI 321 in as-welded and PWTA conditions.

1. Microhardness fluctuates across the weld zone, highest at the weld zone and lowest at base metal. At the same time, microhardness decreases along the weld centerline while traversing from bottom to top.

2. The tensile specimens extracted from the bottom section possess maximum UTS i.e., $575 \mathrm{~N} / \mathrm{mm}^{2}$, and least were for the top section, i.e., $550 \mathrm{~N} / \mathrm{mm}^{2}$.

3. Formation of $\mathrm{MC}(\mathrm{TiC})$ and $\mathrm{M}_{26} \mathrm{C}_{6}\left(\mathrm{Cr}_{26} \mathrm{C}_{6}\right)$ in the austenite matrix after thermal aging at $750^{\circ} \mathrm{C}$ for 24 hours reduced the impact toughness of the weld joint.

4. Reduced ferrite content after thermal aging resulted in a fall in microhardness.

5. The UTS remained unchanged as compared to a base metal, but there was an increase in yield strength after thermal aging. Hence, the percentage elongation is also increased.

\section{Acknowledgments}

The authors wish to acknowledge the Department of Mechanical Engineering, IKG Punjab Technical University Kapurthala, IIT Ropar, SLIET Longowal, and PEC Chandigarh to provide the support lab facilities.

\section{References}

[1] X. Zhang, E. Ashida, S. Tarasawa, Y. Anma, M. Okada, S. Katayama, M. Mizutani: J Laser Appl, 23 (2011) 022002 1-7.

[2] R. Rai, P. Burgardt, J.O. Milewski, T.J. Lienert, T. Debroy: J Phys D Appl Phys, 42 (2009) 54-61.

[3] R.K. Buddu, N. Chauhan, P.M. Raole, H. Natu: Fusion Eng Des, 95 (2015) 34 43.

[4] K. Guan, X. Xu, H. Xu, Z. Wang: Nucl Eng Des, 235 (2005) 2285-2294.

[5] G. Green, R. Higginson, S. Hogg, S. Spindler, C. Hamm, J. Najorka: Mater Sci Technol (United Kingdom), 31 (2015) 418-425.

[6] I. Hajiannia, M. Shamanian, M. Kasiri: Mater Des, 50 (2013) 566-573.

[7] A.F.Padilha, R.L.Plaut, and P.R.Rios, Stainless steels heat treatment (Chapter 12) (2007) 695-735.

[8] K.S. Prasad, C.S. Rao, D.N. Rao, in: Procedia Eng. 97 (2014) 752-757.

[9] J. Swaminathan, R. Singh, M.K. Gunjan, B. Mahato: Eng Fail Anal, 18 (2011) 2211-2221.

[10] A. Pardo, M.C. Merino, A.E. Coy, F. Viejo, M. Carboneras: R. Arrabal, 55 (2007) 2239-2251.

[11] M.E. Wilms, V.J. Gadgil, J.M. Krougman, B.H. Kolster: Mater High Temp, 9 (1991) 160-166.

[12] Y. Minami, H. Kimura, M. Tanimura: J Mater Energy Syst, 7 (1985) 45-54. 
[13] M. Schwind, J. Källqvist, J.O. Nilsson, J. Ågren, H.O. Andrén: Acta Mater, 48 (2000) 2473-2481.

[14] S. Ghosh Chowdhury, N.K. Mukhopadhyay, G. Das, S.K. Das, D.K. Bhattacharya: Eng Fail Anal, 5 (1998) 205-218.

[15] S. Nhi, A. Shokuhfakhodcar, S.A. Iraj, B.G. Thomas: J Press Vessel Technol Trans ASME, 137 (2015) 061405 1-4.

[16] G. Zhang, C.S. Wu, X. Liu: J Mater Process Technol, 215 (2015) 71-78.

[17] A. Doomra, S.S. Sandhu, B. Singh: Metall Mater Eng, 26 (2020) 279-292.

[18] H. Inoue, T. Koseki, S. Ohkita, M. Fuji: Sci Technol Weld Join, 5 (2000) 385396.

[19] H. Inoue, T. Koseki, S. Okita, M. Fuji: Weld Int, 11 (1997) 876-887.

[20] J. Yan, M. Gao, X. Zeng: Opt Lasers Eng, 48 (2010) 512-517.

[21] S.C. Tjong, S.M. Zhu, N.J. Ho, J.S. Ku: J Nucl Mater, 227 (1995) 24-31.

[22] B.S.S. Yilbas, M. Sami, J. Nickel, a. Coban, S. a. M.A.M. Said: J Mater Process Technol, 82 (1998) 13-20.

[23] S.A.A. Akbari Mousavi, A.R. Sufizadeh: Mater Des 30 (2009) 3150-3157.

[24] J. Singh, A.S. Shahi: J Mater Process Tech, 272 (2019) 137-148.

[25] R. Higginson, G. Green, S. Hogg, S. Spindler, C. Hamm, 8th Eur. Stainl. Steel Duplex Stainl. Steel Conf. 2015. (2015) 549-558.

[26] S. Wang, Y. Huang, L. Zhao: Chinese J Aeronaut, 31 (2017) 363-369.

[27] K.S. Guan, X.D. Xu, Y.Y. Zhang, Z.W. Wang: Eng Fail Anal, 12 (2005) 623633.

[28] ISO 16834, International Standard International Standard, 61010-1 @ Iec2001. 2006 (2006) 13.

[29] V. Moura, A.Y. Kina, S.S.M. Tavares, L.D. Lima, F.B. Mainier: Journal of materials science, 43 (2008) 536-540.

[30] American Society of Testing and Materials (ASTM), ASTM Stand. 14 (2002) 124.

[31] ASTM E 23-12c, Standards. i (2013) 1-25.

[32] ASTM E8, Annu. B. ASTM Stand. 4. (2010) 1-27.

[33] C.C. Hsieh, D.Y. Lin, M.C. Chen, W. Wu: Mater Trans, 48 (2007) 2898-2902.

[34] M. Alali, I. Todd, B.P. Wynne: Mater Des, 130 (2017) 488-500.

[35] K. Devendranath Ramkumar, B. Pavan, V. Chandrasekar: J Manuf Process, 32 (2018) 582-594.

[36] A. Kumar, S.S. Sandhu, B. Singh, Springer International Publishing, 2020.

[37] D. Karthik, S. Swaroop: Surf Coatings Technol, 291 (2016) 161-171.

[38] V. Muthupandi, P. Bala Srinivasan, V. Shankar, S.K. Seshadri, S. Sundaresan: Mater Lett, 59 (2005) 2305-2309.

[39] A.H.I. Mourad, A. Khourshid, T. Sharef: Mater Sci Eng A, 549 (2012) 105-113.

[40] N. Venkateswara Rao, G. Madhusudhan Reddy, S. Nagarjuna: Mater Des, 32 (2011) 2496-2506.

[41] A. Kumar, B. Singh, S.S. Sandhu: Fusion Eng Des, 159 (2020) 111949 1-9.

[42] M. Sharifitabar, A. Halvaee: Mater Des, 31 (2010) 3044-3050.

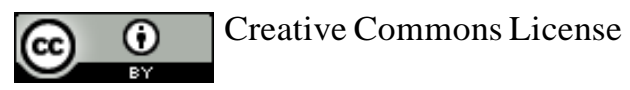

This work is licensed under a Creative Commons Attribution 4.0 International License. 